\title{
On the possibility of the 2011 Tohoku-oki earthquake reactivating Shinmoe-dake volcano, southwest Japan: insights from strain data measured in vaults
}

\author{
K. Yamazaki ${ }^{1,2}$, M. Teraishi ${ }^{1,2}$, S. Komatsu ${ }^{1,3}$, Y. Sonoda ${ }^{1,3}$, and Y. Kano ${ }^{2}$ \\ ${ }^{1}$ Miyazaki Observatory, Disaster Prevention Research Institute, Kyoto University, 3884, Kaeda, Miyazaki 889-2161, Japan \\ ${ }^{2}$ Research Center for Earthquake Prediction, Disaster Prevention Research Institute, Kyoto University, Gokasyo, Uji, \\ Kyoto 611-0011, Japan \\ ${ }^{3}$ Division of Technical Affairs, Disaster Prevention Research Institute, Kyoto University, Gokasyo, Uji, \\ Kyoto 611-0011, Japan
}

Received: 13 April 2011 - Revised: 31 August 2011 - Accepted: 13 September 2011 - Published: 29 September 2011

\begin{abstract}
The Shinmoe-dake volcano in southwest Japan, which produced its first major eruption in $52 \mathrm{yr}$ on 26 January 2011 but had been quiescent since 1 March, re-erupted on 13 March. It was only two days after the occurrence of the $M=9.0$ Tohoku-oki earthquake in eastern Japan. The coincidence of the two events raises the question of whether the earthquake triggered the volcanic activity. As a provisional but rapid assessment of this question, we examined highresolution strain data at a site located $18 \mathrm{~km}$ from Shinmoedake. In terms of the Tohoku-oki earthquake, three points can be drawn from the strain data: (1) static strain changes were less than $0.05 \times 10^{-6}$, which is too small to trigger an eruption; (2) the amplitudes of dynamic strain changes are on the order of $10^{-6}$, which may trigger seismicity or volcanic eruption; and (3) strain rates were not accelerated, which indicates no significant change in magma pressure. Comparing these results with reports of other eruptions coincident with seismic events, and considering a scenario in which a seismic event triggered an eruption, we tentatively conclude that the eruption on 13 March was not a triggered event. However, this conclusion may be revised after analyzing seismic data.
\end{abstract}

\section{Introduction}

The fourth largest earthquake in the last $100 \mathrm{yr}$ occurred on 11 March 2011 off the Pacific coast of Tohoku, Japan. The large magnitude of this earthquake (hereafter, the Tohoku-oki earthquake) $(M=9.0)$ produced seismic waves and resultant

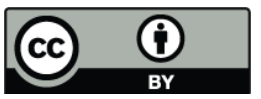

Correspondence to: K. Yamazaki (kenichi@ rcep.dpri.kyoto-u.ac.jp) crustal deformation in the region, raising fears of further disasters, including earthquake-triggered volcanic eruptions as well as triggered seismicity. Observations confirm that earthquakes are frequently followed by volcanic activity (e.g. Linde and Sacks, 1998). All $M \geqq 9.0$ earthquakes in the last $100 \mathrm{yr}$ have been followed by significant volcanic eruptions; i.e. Kamchatka, $1952(M=9.0)$; Chile, $1960(M=9.5)$; Alaska, $1964(M=9.2)$; and Sumatra-Andaman, 2004 and 2005 ( $M=9.3$ and $M=8.7$, respectively) (e.g. Walter and Amelung, 2007).

The Shinmoe-dake volcano in Kirishima volcanic group, in southwest Japan (Fig. 1), is of major concern in terms of earthquake-triggered eruptions in Japan. Shinmoe-dake produced its first major eruption in $52 \mathrm{yr}$ on 26 January 2011, followed by persistent activity (see the Web site of Earthquake Research Institute, University of Tokyo: http:// outreach.eri.u-tokyo.ac.jp/eqvolc/201101_shinmoe/eng/, last access: 11 April 2011). Although the volcano had been quiescent since 1 March, a relatively large eruption occurred on 13 March, two days after the Tohoku-oki earthquake. The coincidence of the two events, the Tohoku-oki earthquake and the revival of Shinmoe-dake volcanic activity, caused anxiety among local residents and instigated demands for an investigation of a possible relationship between volcanic activity and the earthquake.

One promising method for monitoring active volcanoes is through high-resolution strain measurements (e.g. Ishihara, 1990; Iguchi et al., 2008). We have observed crustal strains in vaults at Isa Observatory (ISA; location: $32^{\circ} 00^{\prime} 14.4^{\prime \prime} \mathrm{N}$, $130^{\circ} 43^{\prime} 31.44^{\prime \prime}$ E; Fig. 1b), using extensometers composed of 30-m lengths of super-invar rods installed in tunnels in three independent horizontal directions: $\mathrm{E} 1\left(\mathrm{~N} 37^{\circ} \mathrm{W}\right)$, E2(N53 $\left.{ }^{\circ} \mathrm{E}\right)$, and E3(N82 ${ }^{\circ}$ W) (Takada et al., 1987; Harada et

Published by Copernicus Publications on behalf of the European Geosciences Union. 
al., 2003). Because of its proximity to Shinmoe-dake (within $\sim 18 \mathrm{~km}$ ), strain data from ISA are expected to provide timely monitoring of the effects of the Tohoku-oki earthquake on crustal strain in the region, and of potential impacts on activity at Shinmoe-dake.

In this paper, strain data are reported with the aim of addressing the following points: whether external forces (related to the Tohoku-oki earthquake) acting on Shinmoedake were sufficiently large to trigger a volcanic eruption, and whether strain rates associated with magma accumulation show marked variations before and after the Tohoku-oki earthquake. The relationship between the earthquake and the eruption is discussed based on the strain data. A comprehensive assessment of the earthquake-volcano relationship at Shinmoe-dake would require detailed studies based on geophysical datasets, whereas we only examine strain data. Nevertheless, we seek a rapid, although tentative, answer to the question of whether the eruption on 13 March was triggered by the Tohoku-oki earthquake, because such information would address public concern, even if a definitive answer is not immediately available.

\section{Changes in strain simultaneous with the Tohoku-oki earthquake}

To assess the plausibility of an earthquake-triggered eruption, it is necessary to precisely determine the nature of changes in strain near the volcano following the earthquake. Two types of strain change should be considered as a cause of triggering: static strain change, which is defined as an offset at the time of a seismic event, and dynamic strain change, which accompanies the propagation of seismic waves. Here, strain data are used to evaluate both of these effects.

\subsection{Static changes in strain}

Theoretically, static changes in strain at an arbitrary location are calculated by assuming a fault model and the elasticity of the Earth. Figure 1a shows an example of areal strain calculated in this way, based on a preliminary fault model proposed by the Geospatial Information Authority of Japan (GSI) (http://www.gsi.go.jp/cais/topic110313-index. html; last access, 11 April 2011) and using an analytical solution of strain derived by Okada (1992). However, the calculated strains may differ from in situ strains because the detailed structure of the Earth cannot be incorporated into the theoretical model. Thus, estimates of coseismic strain based on direct strain measurements near the volcano are preferable to theoretical calculations.

Coseismic changes in strain near Shinmoe-dake were estimated using data collected from 9 to 13 March, a 5-day period that brackets the date of the Tohoku-oki earthquake. We assume that the strain data decompose to the following factors: increase/decrease at a constant rate, tidal variations

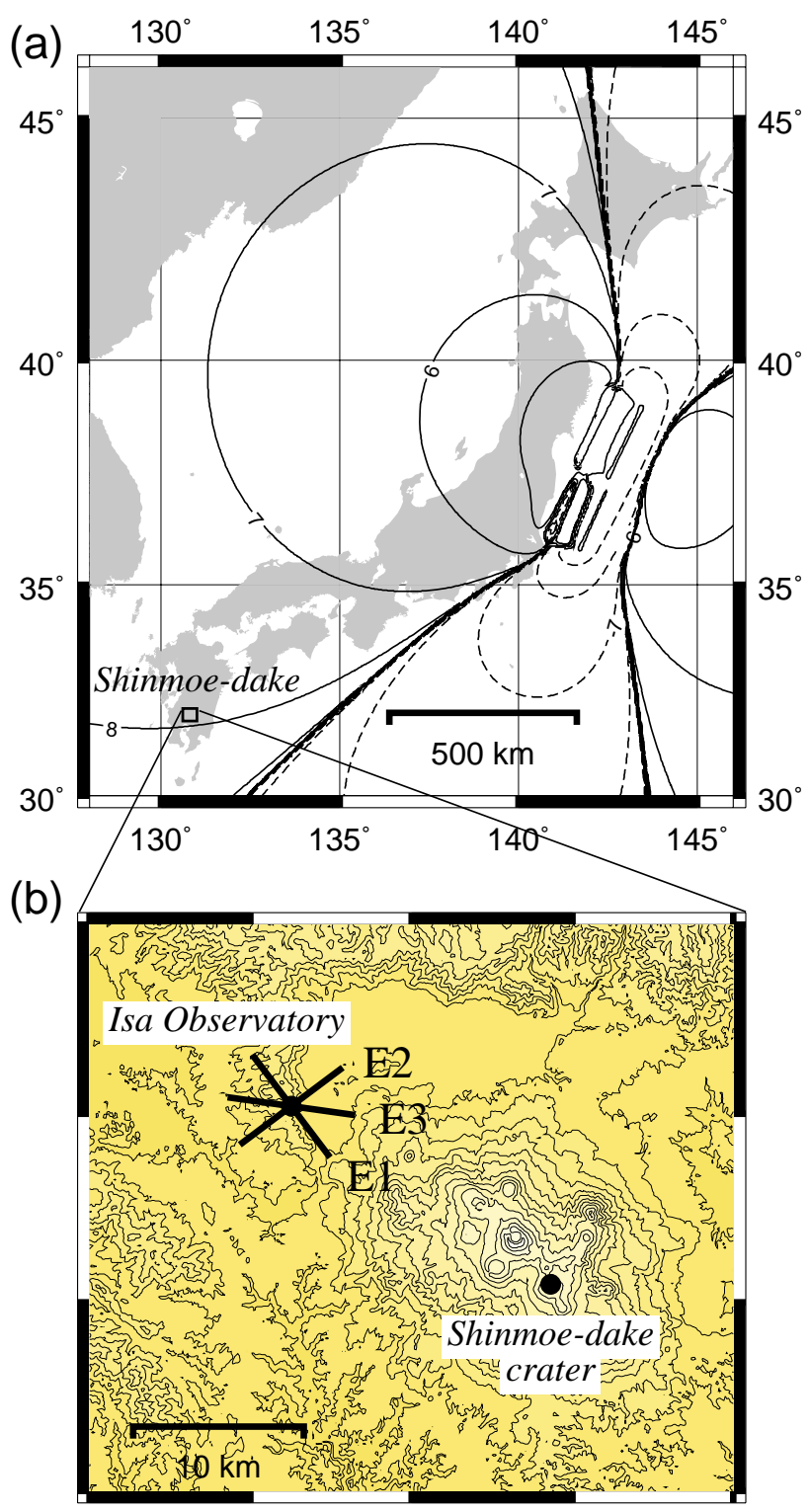

Fig. 1. (a) Map showing the location of the Shinmoe-dake volcano, together with contours showing calculated areal strain due to the Tohoku-oki earthquake. Contour intervals represent logarithmicscale increments; positive changes (expansion), negative changes (contraction), and null changes are indicated by solid lines, dashed lines, and a thick solid line, respectively. (b) Topographic map of the area around Shinmoe-dake, showing the location of the ISA site. Contour intervals are $100 \mathrm{~m}$. Thick bars show the orientations of vaults (E1, E2, and E3) in which extensometers are installed.

with a lunar semidiurnal $\left(\mathrm{M}_{2}\right)$ and luni-solar diurnal $\left(\mathrm{O}_{1}\right)$ periodicity, offsets due to the Tohoku-oki earthquake, and random noise. The contribution of each factor to the total strain is determined by a least squares method. To minimize the effects of post-seismic deformation not considered in the above model, data from 15:00-19:59 local time on the 


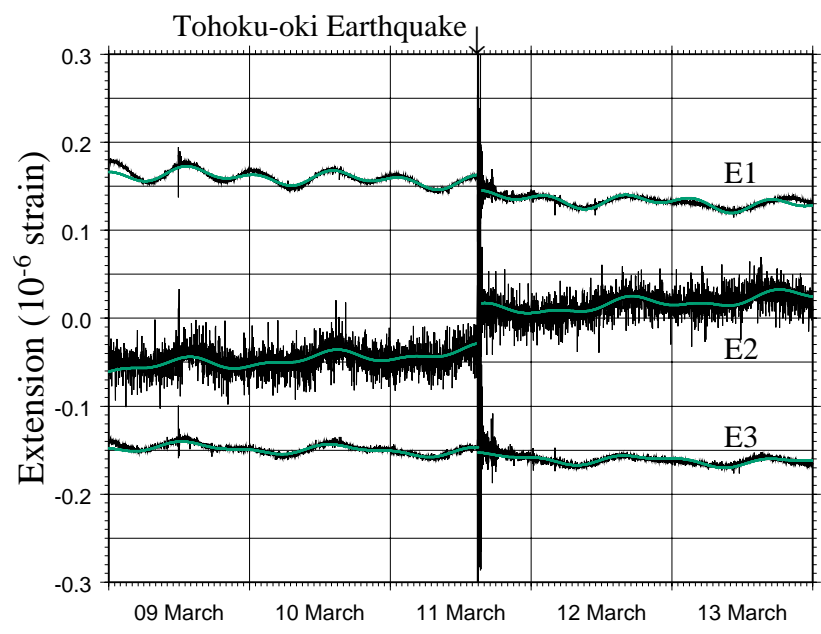

Fig. 2. Variations in strain in the E1, E2, and E3 directions during 9-13 March 2011. Black and green lines represent the original data resampled at 1-min intervals and corrected values after removing random noise, respectively.

day of the Tohoku-oki earthquake were ignored in the fitting procedure. Because of this selection, the determined offsets include not only changes simultaneous with the mainshock of the Tohoku-oki earthquake, but also changes due to aftershocks and post-seismic deformation during the ignored period of time.

Figure 2a shows temporal variations in the strain data after removing random noise (green curves) and the original data (black dots). Coseismic changes in strain, in the E1, E2, and $\mathrm{E} 3$ directions, were determined to be $-0.016 \times 10^{-6}$, $+0.045 \times 10^{-6}$, and $-0.007 \times 10^{-6}$, respectively. The corresponding areal strain, which is a potentially important factor in the static triggering of eruptions, was $+0.029 \times 10^{-6}$.

\subsection{Dynamic changes in strain}

The amplitudes of dynamic changes in strain produced by the Tohoku-oki earthquake are estimated by analyzing the data with a sampling interval of $1 \mathrm{~s}$ (Fig. 3). Unfortunately, the extensometers at ISA are not suitably designed to measure dynamic strains arising from earthquakes, because they were originally installed to observe long-term crustal movements (Takada et al., 1987). Consequently, the observation ranges are rather narrow in terms of recording the entire picture of dynamic strain changes. Some of the recorded values are saturated in E2 and E3. However, this problem is related to data-logging rather than to operation of the extensometer. Therefore, it is possible to obtain rough estimates of the amplitudes of dynamic strains.

The recorded values for the E1 component are not saturated; the peak-to-peak amplitude is estimated to be $2 \times 10^{-6}$. For the E3 component, positive fluctuations (i.e. extension) are correctly recorded, whereas negative fluctuations (i.e.

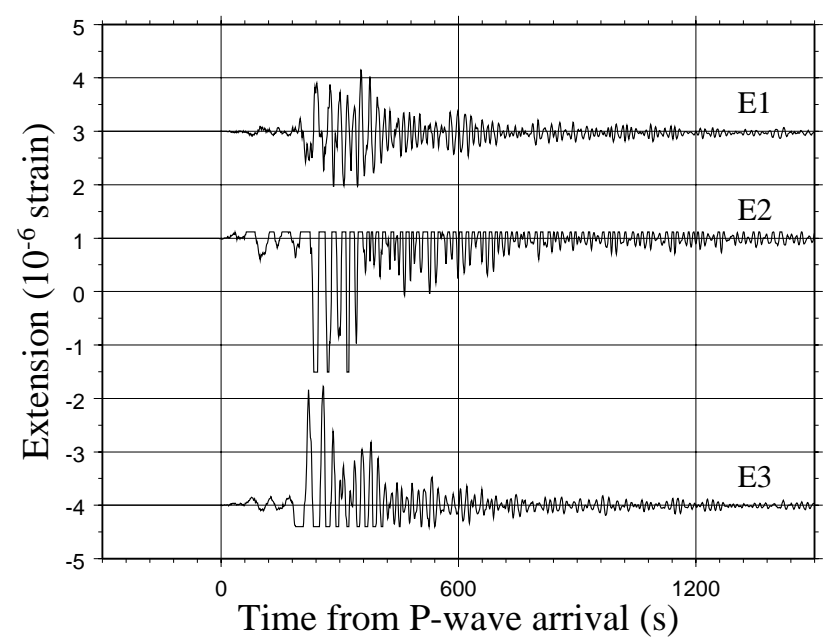

Fig. 3. Variations in strain in the E1, E2, and E3 directions between 14:44 and 15:14 (LT = UT + 9) on 11 March 2011. Zero on the horizontal axis represents the approximate arrival time of seismic waves from the Tohoku-oki earthquake.

contraction) are saturated. However, it is reasonable to assume that the waveforms of strain in horizontal components are approximately symmetrical, although this assumption is sometimes invalid for vertical components (i.e. the trampoline effect proposed by Aoi et al., 2008). Therefore, the peakto-peak value of dynamic strain in E3 is twice the maximum positive fluctuation in E3; i.e. approximately $4 \times 10^{-6}$. The scale of the dynamic amplitudes in E2 is rather difficult to estimate because both the positive and negative fluctuations are saturated in the recorded values (Fig. 2b). However, the unsaturated parts of the waveforms suggest that the dynamic strains in E2 are no more than twice those in E3 and no more than three times those in E1. Therefore, peak-to-peak values in E2 strain are up to $8 \times 10^{-6}$. In summary, the observed dynamic strains are on the order of $10^{-6}$.

\section{Trend in strain rate before and after the Tohoku-oki earthquake}

Strain data are expected to indicate changes in the volume or pressure of magma chambers. Since magma chambers related to the Shinmoe-dake eruptions are assumed to be considerably smaller than the distance between Shinmoe-dake and the ISA site, they can be reasonably approximated by a point source. The strain field caused by a point pressure/volume source is expressed by an analytically closed form (Yamakawa, 1955). Positive increments of volume or pressure cause negative strain (contraction) in the radial direction and positive strain (extension) in the transverse direction, except for the area immediately above the magma chamber (Fig. 4). The E1 and E2 directions approximately correspond to the radial and transverse directions relative to 

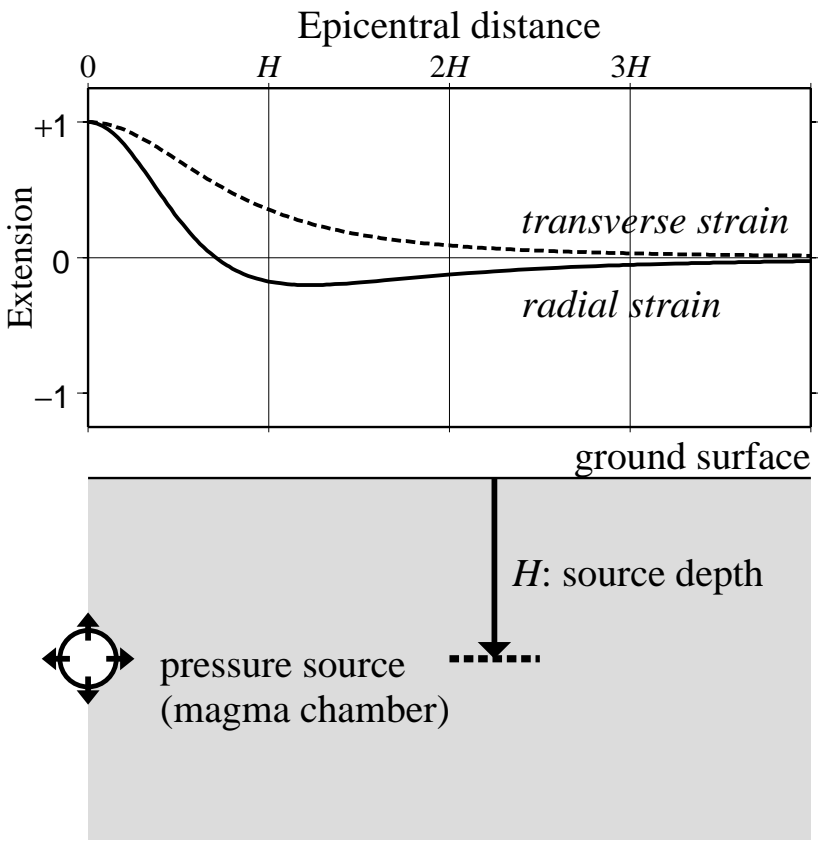

Fig. 4. Illustration of expanding point source in an elastic half space (lower panel) and the corresponding strains in radial and transverse directions normalized by the strain immediately above the point source (upper panel).

Shinmoe-dake; therefore, the E1 and E2 strain approximately indicate the magnitude of expansion/contraction and location of the magma chamber.

The strain data at ISA were validated by examining recordings during times of volcanic activity in the absence of the remote earthquake. In 2011, the most prominent activity at Shinmoe-dake was related to three subplinian eruptions that occurred on 26 and 27 January. Extensometers accurately recorded these eruptions in detail (Fig. 5). Moreover, the location of the magma chamber calculated from the strain data is consistent with the location estimated from other kinds of data, including tiltmeters and GPS (Yamazaki et al., 2011). This result implies that the strain data from the ISA vault provide a means to monitor temporal changes in the volume of the magma chamber.

Figure 6 a shows the original time series of strain at ISA. The data must be interpreted with caution because strain data obtained in vaults are commonly influenced by miscellaneous factors such as loading by groundwater (e.g. Kasahara et al., 1983). In the case of the ISA data, severe distortions of strain appear mainly in the rainy season (June to August), and attenuated variations persist throughout the year (e.g. Fig. 2 in Harada et al., 2003, and Fig. 6 in Teraishi et al., 2009).

To reduce the effects of unexpected signal distortions, we refer to an assumption that strain rates related to activity at Shinmoe-dake should be zero from 1 to 8 February 2011 (K. Ishihara, personal communication, 2011). This

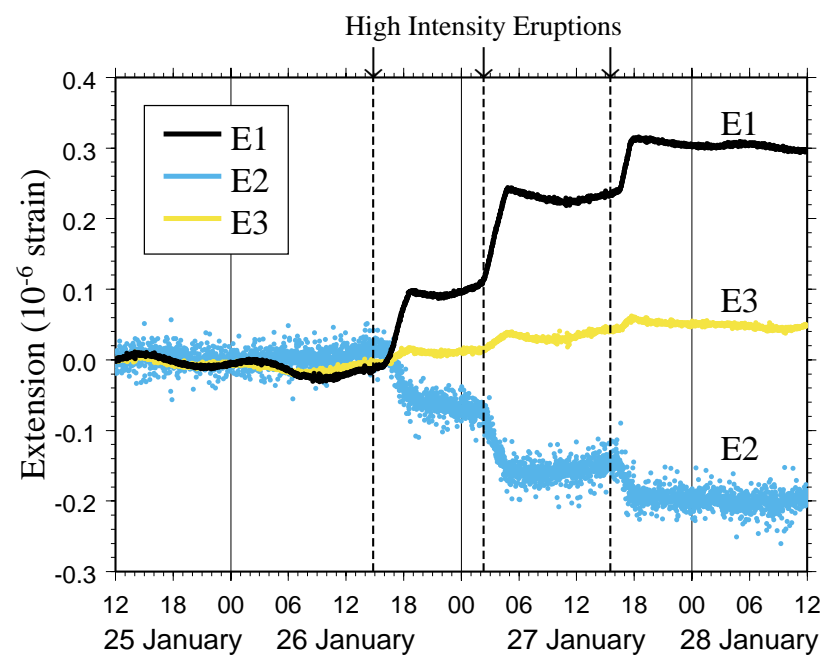

Fig. 5. Strain at the ISA site during the period from 12:00 (local time) on 25 January to 12:00 on 28 January 2011.

assumption is based on the fact that no significant crustal deformations were recorded around Shinmoe-dake by other geophysical instruments during this time, including a GPS network deployed by GSI. Thus, trends appearing between 1 and 8 February are attributed to other origins, including groundwater loading and other meteorological factors. On this basis, the time series of strain data were corrected. The E1, E2, and E3 components show linear trends on 1 and 8 February (dashed lines in Fig. 6a), but these were subsequently removed from the original time series (thick curves in Fig. 6a). The coseismic steps in strain (Fig. 2) were also removed.

The corrected time series are shown in Fig. 6b. The main features of the corrected time series of strain are summarized as follows. Before the Tohoku-oki earthquake, strain rates in the $\mathrm{E} 1$ and $\mathrm{E} 2$ directions were negative and in the E3 direction, positive. Considering the orientations of the vaults relative to the location of Shinmoe-dake (Fig. 1), the observed strain rates correspond to dilatation of a magma chamber beneath Shinmoe-dake (Fig. 3). After the Tohoku-oki earthquake, strain accumulation rates in all directions decelerated for several days, indicating that the expansion rate of the magma chamber was temporarily diminished by the occurrence of the Tohoku-oki earthquake.

During the period from 22 to $25 \mathrm{March}$, maintenance work at ISA, including electrical service maintenance, may have caused disturbances or distortions of strain data (Fig. 5); thus, data during and after this period should be interpreted with caution. For example, the rapid increase in strain in the E2 direction on 22 March may be a result of maintenance work, and thus cannot be considered to represent expansion of the magma chamber at this time.

The increase of strain in the E2 direction between 18 and 21 March should also be carefully evaluated. Although the 
(a) Original time series

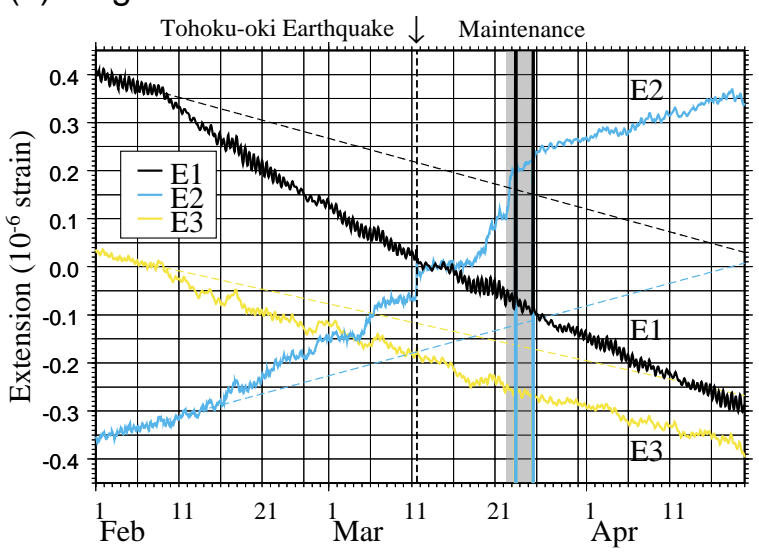

(b) Corrected time series

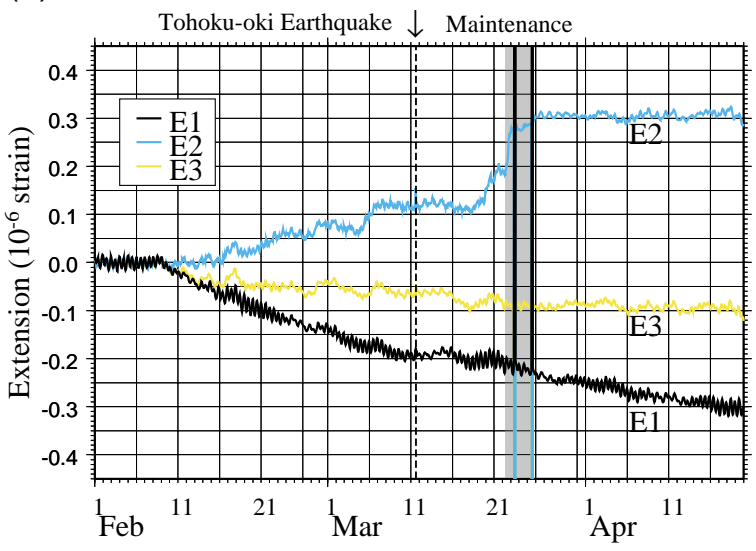

Fig. 6. (a) Original time series of strain in the E1, E2, and E3 directions during the period from 1 February to 7 April 2011. Dashed lines show linear trends determined for the period from 1 to 8 February. The region highlighted in gray indicates a period of facility maintenance, which may have influenced the data. (b) Corrected time series of strain after removing linear trends (dashed lines in (a)) and coseismic changes (Fig. 2).

variations during this time appear large, other fluctuations of strain in the same direction and with approximately the same amplitude are observed at other times, such as between 4 and 6 March. Moreover, a corresponding decrease of strain in E1 and $\mathrm{E} 3$ directions is not observed, implying that it cannot be attributed to changes in pressure of a point source beneath the volcano (see Fig. 4). Therefore, it is difficult to establish a definitive causal relationship between post-earthquake strain fluctuations and Shinmoe-dake volcanic activity that occurred at this time.

\section{Discussion}

Mechanisms for triggering eruptions are of two types: static triggering caused by static deformation of the crust, and dynamic triggering caused by the effects of passing seismic waves (e.g. Hill et al., 2002). Based on the strain data described above, we discuss the possibility of triggering in the case of the eruption on 13 March.

The plausibility of static triggering of the 13 March Shinmoe-dake eruption can be assessed by examining the magnitudes of static changes in strain near the volcano. The distance between Shinmoe-dake and the focal area of the Tohoku-oki earthquake is considerably larger than the distance between ISA and Shinmoe-dake. Therefore, it is reasonable to assume that the ISA vaults and the volcanic system of Shinmoe-dake are subjected to the same regional stress field.

However, we cannot be sure that the strain at ISA is an accurate reflection of the regional stress. Given that the deformation of ISA vaults may be influenced by topographic effects, strains at ISA may differ from the average regional strain.

To confirm the validity of using strain data collected at ISA, we compare observed and theoretical strain arising from tidal forces. Figure 7 shows an example of observed variations in strain and theoretical tides in strain calculated by GOTIC2 (Matsumoto et al., 2001). For the E2 components, the observed and calculated tidal variations show good agreement in both amplitude and phase. For the E1 and E3 components, in contrast, the amplitudes of observed tidal variations are smaller than those calculated, possibly due to errors in the calculation or the influence of site effects on the strain data at ISA. If the former is the case, the inconsistency presents no problem. Even if the later is the case, the difference between observed and calculated amplitudes is less than a factor of two.

Based on the above discussion, strain data from ISA vaults are directly used to evaluate the possibility of static triggering. The dilatation observed during the 11 March earthquake (on the order of $10^{-8}$ ) seems too small to trigger eruptions. Previous studies suggest that many earthquaketriggered eruptions have occurred in areas where volumetric strain was on the order of $10^{-5}$ (Barrientos, 1994; Walter and Amelung, 2007). Although some volcanic eruptions may be triggered by relatively small stresses, on the order of $0.01 \mathrm{MPa}$ (e.g. Nostro et al., 1998), these values are still larger than those observed near Shinmoe-dake, where calculated stresses corresponding to observed strains are not larger than $0.005 \mathrm{MPa}$, even assuming a stiff crust with elastic constants of the order of $100 \mathrm{GPa}$.

It is not certain that the stress acting on magma or a conduit is representative of the regional stress. However, in studies of triggering eruptions, stress is not measured or considered at the exact location of the magma system; instead, regional stress/strain (including the area of the volcano) is considered (e.g. Barientos, 1994). Consequently, it is valid to compare the strain/stress estimated above with other cases of earthquake-triggering eruptions. In summary, our observations demonstrate that changes in strain (and corresponding stresses) accompanying the Tohoku-oki earthquake were too 


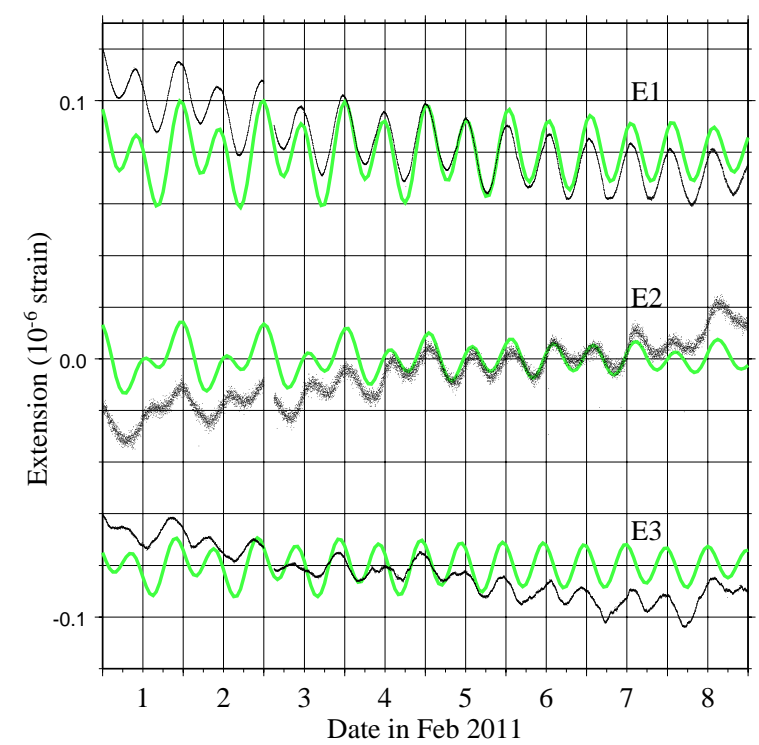

Fig. 7. Example of a comparison between observed strain variations (black) and theoretically predicted tidal variations (grey) in each direction.

small to have triggered the eruption of Shinmoe-dake. Therefore, the possibility of static triggering is considered highly unlikely.

In contrast to static triggering, the possibility of dynamic triggering mechanisms is not inconsistent with the amplitudes of observed dynamic strain changes. Intuitively, dynamic triggering by the Tohoku-oki earthquake seems implausible. Ground motions in the area around Shinmoe-dake were not as large as those generated by local earthquakes. Indeed, data from the KiK-net and K-NET systems, administered by the National Research Institute for Earth Science and Disaster Prevention, Japan (NIED), indicate peak ground motions and peak ground motion acceleration around Shinmoe-dake of less than $0.1 \mathrm{~cm} \mathrm{~s}^{-1}$ and 1.0 gal, respectively, in the case of the Tohoku-oki earthquake. Nevertheless, the observed amplitudes of dynamic strain changes are on the order of $10^{-6}$, which may be sufficiently large to trigger eruptions.

If dynamic triggering of an eruption occurs, additional mechanisms are necessary to maintain the increased pressure in the magmatic system or to enhance the movement of magma to the surface, because dynamic strain changes are transitory phenomena (Manga and Brodsky, 2006). The plausibility of triggering in this way should be examined by seeking evidence of such converting mechanisms.

A plausible scenario that would explain dynamic triggering involves dynamic stress converted to permanent stress increments by certain mechanisms, including the growth of bubbles in magma (e.g. Woods and Cardoso, 1997; Huppert and Woods, 2002). If this had been the case for Shinmoedake, we would expect to observe increments in pressure.
However, this prediction contradicts our observations: the strain data at ISA indicate no significant post-earthquake deformation that might be associated with volume changes of the magma chamber (Fig. 6b). This result indicates that dynamic triggering by the assumed scenario is not plausible, at least during several days after the earthquake (including the eruption on 13 March).

In terms of dynamic triggering, it may be necessary to consider the possibility that earthquake-triggering eruptions occur without geodetic manifestations. A plausible scenario in this regard is that the Tohoku-oki earthquake triggered a local earthquake swarm around Shinmoe-dake, and that the swarm triggered further unrest in the volcanic system. Earthquake swarms commonly follow seismic waves with significant amplitudes from remote earthquakes (e.g. Hill et al., 1993; Husen et al., 2004; Yukutake et al., 2011). In the case of such a scenario, strain data would provide little insight into this process; seismic observations would be required. Volcanologists are currently studying the record of seismic activity at Shinmoe-dake, and the results of this analysis may require a revision of the conclusions of this study.

Finally, we note that the above discussion applies only to the eruption event on 13 March 2011, which occurred shortly after the Tohoku-oki earthquake on 11 March 2011. It has been proposed that earthquake-triggering of volcanic activity involves a considerable time lag (e.g. Walter and Amelung, 2007). For example, one important triggering mechanism, involving viscoelastic relaxation of the crust (Marzocchi, 2002; Marzocchi et al., 2002), operates at time scales of at least several months. The question of whether such triggering events are feasible could not be answered at the time of writing. This problem requires a future analysis of sufficiently long time series of geophysical data from various sources.

\section{Conclusions}

We derived three points from strain data at the ISA site relevant to the possibility of earthquake-triggering eruptions: (1) static dilatation near Shinmoe-dake caused by the earthquake was less than $0.05 \times 10^{-6}$; (2) the amplitudes of dynamic strain due to the earthquake are on the order of $10^{-6}$; and (3) strain rates at the ISA site did not accelerate at around the time of the earthquake. The possibility of static triggering is highly unlikely, considering point (1), whereas the possibility of dynamic triggering is not inconsistent with point (2). If we assume that dynamic triggering occurred via a magmatic process, it would be reasonable to expect increments of pressure in the magma at the time of the earthquake, but this was not observed (3). Therefore, the strain data do not support the hypothesis that the re-eruption of Shinmoe-dake on 13 March 2011 was triggered by the Tohoku-oki earthquake on 11 March 2011. However, revision of this conclusion may be necessary after a careful analysis of seismic data around Shinmoe-dake. 
Acknowledgements. The ISA facilities are maintained in cooperation with the staff of the Sakurajima Volcano Research Center, Disaster Prevention Research Institute, Kyoto University. A slip model proposed by GSI was used to calculate static strain changes. Data from KiK-net and K-NET, deployed by NIED of Japan, were assessed to estimate the intensities of ground motions. Generic Mapping Tools software (Wessel and Smith, 1998) was used to prepare the illustrations. The authors are grateful to K. Ishihara for his advice on correcting the strain data, and to two reviewers for their comments, which resulted in substantial improvements to the manuscript. The publication of this work was partially supported by the Ministry of Education, Culture, Sports, Science and Technology of Japan, under its Observation and Research Program for Prediction of Earthquakes and Volcanic Eruptions.

Edited by: J. Marti

Reviewed by: W.-C. Lai and another anonymous referee

\section{References}

Aoi, S., Kunugi, T., and Fujiwara, H.: Trampoline effect in extreme ground motion, Science, 322, 727-730, doi:10.1126/science.1163113, 2008 .

Barrientos, S. E.: Large thrust earthquakes and volcanic eruptions, Pure Appl. Geophys., 142, 225-237, doi:10.1007/BF00875972, 1994.

Harada, M., Furuzawa, T., Teraishi, M., and Ohya, F.: Temporal and spatial correlations of the strain field in tectonic active region, southern Kyusyu, Japan, J. Geodyn., 35, 471-481, doi:10.1016/S0264-3707(03)00008-5, 2003.

Hill, D. P., Pollitz, F., and Newhall, C.: Earthquake-volcano interactions, Physics Today, 55, 41-47, doi:10.1063/1.1535006, 2002.

Hill, D. P., Reasenberg, P. A., Michael, A., Arabaz, W. J., Beroza, G., Brumbaugh, D., Brune, J. N., Castro, R., Davis, S., dePolo, D., Ellsworth, W. L., Gomberg, J., Harmsen, S., House, L., Jackson, S. M., Johnston, M. J. S., Jones, L., Keller, R., Malone, S., Munguia, L., Nava, S., Pechmann, J. C., Sanford, A., Simpson, R. W., Smith, R. B., Stark, M., Stickney, M., Vidal, A., Walter, S., Wong, V., and Zollweg, J.: Seismicity remotely triggered by the magnitude 7.3 Landers, California, earthquake. Science, 260, 1617-1623, doi:10.1126/science.260.5114.1617, 1993.

Huppert, H. E. and Woods, A. W.: The role of volatiles in magma chamber dynamics, Nature, 420, 493-495, doi:10.1038/nature01211, 2002.

Husen, S., Wiemer, S., and Smith, R. B.: Remotely triggered seismicity in the Yellowstone National Park region by the $2002 \mathrm{Mw}$ 7.9 Denali Fault earthquake, Alaska, Bull. Seismol. Soc. Am., 94, S317-S331, doi:10.1785/0120040617, 2004.

Iguchi, M., Yakiwara, H., Tameguri, T., Hendrasto, M., and Hirabayashi, J.: Mechanism of explosive eruption revealed by geophysical observations at the Sakurajima, Suwanosejima and Semeru volcanoes, J. Volcanol. Geotherm. Res., 178, 1-9, doi:10.1016/j.jvolgeores.2007.10.010, 2008.

Ishihara, K.: Pressure sources and induced ground deformation associated with explosive eruptions at an andesitic volcano: Sakurajima volcano, Japan, in: Magma transport and storage, edited by: Ryan, M., John Wiley \& Sons, Chichester, 440 pp., 335-356, 1990.
Kasahara, M., Shichi, R., and Okada, Y.: On the cause of long-period crustal movement, Tectonophysics, 97, 327-336, doi:10.1016/0040-1951(83)90161-0, 1983.

Linde, A. T. and Sacks, I. S.: Triggering of volcanic eruptions, Nature, 395, 888-890, doi:10.1038/27650, 1998.

Manga, M. and Brodsky, E.: Seismic triggering of eruptions in the far field: Volcanoes and geysers, Annu. Rev. Earth Planet. Sci., 34, 263-291, doi:10.1146/annurev.earth.34.031405.125125, 2006.

Marzocchi, W.: Remote seismic influence on large explosive eruptions, J. Geophys. Res., 107(B1), 2018, doi:10.1029/2001JB000307, 2002.

Marzocchi, W., Casarotti, E., and Piersanti, A.: Modeling the stress variations induced by great earthquakes on the largest volcanic eruptions of the 20th century, J. Geophys. Res., 107(B11), 2320, doi:10.1029/2001JB001391, 2002.

Matsumoto, K., Sato, T., Takanezawa, T., and Ooe, M.: GOTIC2: A program for computation of oceanic tidal loading effect, J. Geod. Soc. Japan, 47, 243-248, 2001.

Nostro, C., Stein, R. S., Cocco, M., Belardinelli, M. E., and Marzocchi, W.: Two-way coupling between Vesuvius eruptions and southern Apennine earthquakes, Italy, by elastic stress transfer, J. Geophys. Res., 103, 24487-24424, 1998.

Okada, Y.: Internal deformation due to shear and tensile faults in a half-space, Bull. Seismol. Soc. Am., 82, 1018-1040, 1992.

Takada, M., Furuzawa, T., Ohya, F., Teraishi, M., and Sonoda, Y.: Observation network of crustal activities around the Hyuganada region of Kyusyu, Annuals Disas. Prev. Res. Inst., Kyoto Univ. 30B-1, 29-40, 1987 (in Japanese with English abstract).

Teraishi, M., Onoue, K., Ohya, F., Nakamura, K., Takeuchi, F., Morii, W., Hoso, Y., Sonoda, Y., and Wada, Y.: Seasonal variations in the continuous observations of the crustal movement, Annuals Disas. Prev. Res. Inst., Kyoto Univ., 52B, 285-291, 2009 (in Japanese with English abstract).

Walter, T. R. and Amelung, F.: Volcanic eruptions following $M \geq 9$ megathrust earthquakes: Implications for the Sumatra-Andaman volcanoes, Geology, 35, 539-542, doi:10.1130/G23429A.1, 2007.

Wessel, P. and Smith, W. H. F.: New, improved version of Generic Mapping Tools released, EOS Trans. AGU, 79, 579, doi:10.1029/98EO00426, 1998.

Woods, A. W. and Cardoso, S. S. S.: Triggering basaltic volcanic eruptions by bubble-melt separation, Nature, 385, 518520, doi:10.1038/385518a0, 1997.

Yamakawa, N.: On the strain produced in a semi-infinite elastic solid by an interior source of stress, Zishin 2nd collection, J. Seismol. Soc. Japan, 8, 84-98, 1955.

Yamazaki, K., Teraishi, M., Komatsu, S., and Kano, Y.: Crustal deformation accompanying with activities of Shinmoe volcano observed by extensometers, Paper scheduled to be presented at Volcanological Society of Japan Fall Meeting, Asahikawa, Hokkaido, Japan, 2-4, Oct. 2011.

Yukutake, Y., Honda, R., Harada, M., Aketagawa, T., Ito, H., and Yoshida, A.: Remotely triggered seismicity in Hakone volcano following the 2011 Off the Pacific Coast of Tohoku Earthquake, Earth Planets Space, doi:10.5047/eps.2011.05.004, in press, 2011. 